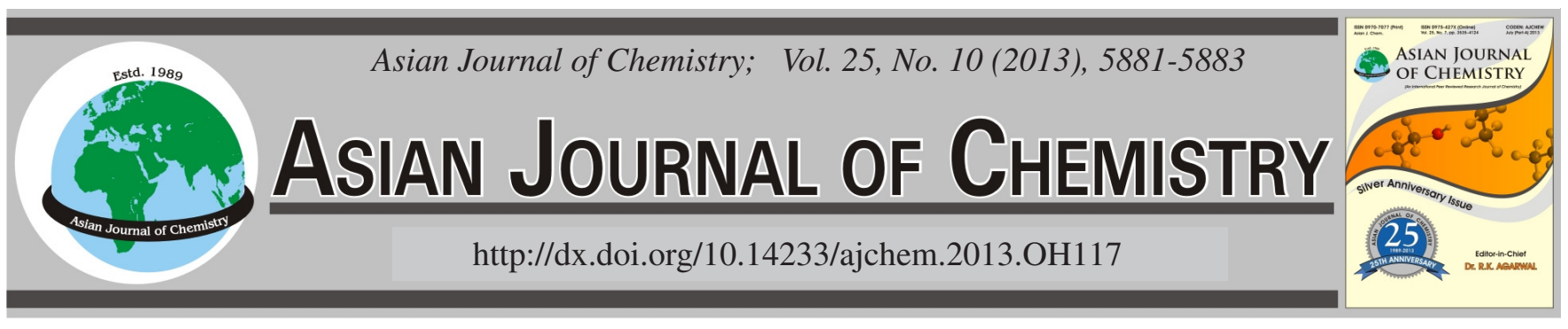

\title{
Preparation and Property Enhancement of Hydroxyapatite/ Poly(vinyl pyrrolidone) Nanocomposites $\dagger$
}

\author{
Yun Wu, Benhong YAnG ${ }^{*}$, Meng Li and Dan LiU
}

Department of Chemical and Materials Engineering, Hefei University, Hefei 230601, P.R. China

*Corresponding author: E-mail: yangbh@hfuu.edu.cn

\begin{abstract}
A series of noval organic-inorganic nanocomposite materials of hydroxyapatite/poly(vinyl pyrrolidone) were synthesized by in situ copolymerization of modified inorganic nanoscale hydroxyapatite and poly(vinyl pyrrolidone). The hydroxyapatite/poly(vinyl pyrrolidone) nanocomposites were characterized by scanning electronic microscope, X-ray diffraction and Fourier transform infrared analysis. The thermogravimetric analysis and differential scanning calorimetry results showed that the thermal properties of hydroxyapatite/poly(vinyl pyrrolidone) nanocomposites were significantly improved compared with the mother poly(vinyl pyrrolidone) polymers.
\end{abstract}

Key Words: Hydroxyapatite, Poly(vinyl pyrrolidone), Organic-inorganic nanocomposites, Thermal properties.

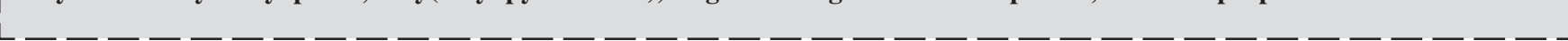

\section{INTRODUCTION}

With the rapid development of society and the progress of technology, organic-inorganic nanocomposite materials have been paid more concern by the scientific and public communities because they could have the combination properties of both organic polymers and inorganic compounds such as processing ability, toughness, low cost and heat resistance, antioxidation as well as good thermal and mechanical properties. Organic-inorganic nanocomposites have become one of the hot spots of materials science ${ }^{1-7}$.

Compared with conventional synthesis methods like physical blending, in this paper, organic-inorganic nanocomposite materials were synthesized using in situ copolymerization method. The inorganic nanoscale hydroxyapatite (Hap) of about $160 \mathrm{~nm}$ long with surface grafted with vinyl groups and vinylpyrrolidone monomers were mixed and undergone in situ free radical copolymerization. The thermal properties of Hap/ PVP nanocomposites were especially studyed.

\section{EXPERIMENTAL}

Calcium chloride, diammonium phosphate, cyclohexane, n-pentanol, TX-100, sodium bisulfate, hydroquinone, methacrylic acid, 1,4-dioxane, tetrahydrofuran, azobisisobutyronitrile (AIBN), $\mathrm{N}$-vinyl pyrrolidone (NVP) were all analytical reagent.

A mixture of $\mathrm{NH}_{4} \mathrm{H}_{2} \mathrm{PO}_{4}(0.3 \mathrm{~mol} / \mathrm{L})$ and $\mathrm{CaCl}_{2}(0.5 \mathrm{~mol} / \mathrm{L})$ was adjusted to $\mathrm{pH} 11$ and heated at $120{ }^{\circ} \mathrm{C}$ for $10 \mathrm{~h}$ in a
Telfon-lined stainless steel hydrothermal reactor. After washing with water, drying, white hydroxyapatite powder was obtained. Hydroxyapatite powder was mixed with $\mathrm{NaHSO}_{4}$, hydroquinone and benzene in a flask, ultrasonically dispersed for about $0.5 \mathrm{~h}$, heated up to $85^{\circ} \mathrm{C}$, added methacrylic acid. After reaction for $10 \mathrm{~h}$, the mixture was filtered and extracted by chloroform, $m$-hydroxyapatite powder was obtained.

The $m$-hydroxyapatite and 1,4-dioxane were added in a flask, ultrasonically dispersed about $30 \mathrm{~min}, \mathrm{NVP}$ and AIBN were added, stirred continuously at $80^{\circ} \mathrm{C}$ for $10 \mathrm{~h}$ in nitrogen protection. The obtained product was dissolved in tetrahydrofuran, slowly added into toluene to wash out impurities. This procedure was repeated three times. The wet product was dried at $40{ }^{\circ} \mathrm{C}$ under vacuum.

\section{RESULTS AND DISCUSSION}

FT-IR: Fig. 1 shows FT-IR absorption spectra of the $m$ hydroxyapatite, pure PVP and Hap/PVP with different contents. In Fig. 1, the Hap/PVPs show the absorption bands of both $m$-Hap and pure PVP, revealing that the in situ copolymerization between $m$-Hap and NVP has happened. Thus, the $m$-Hap/PVP nanocomposites were successfully prepared.

XRD: X-ray diffractions were employed to obtain the structural and crystalline information of the prepared samples. Fig. 2 shows characteristic diffraction peaks of Hap at 25.9, $31.8,32.2$ and $32.9^{\circ}$, which are corresponding to the crystal surfaces of (002), (211), (112) and (300) of Hap, respectively, 


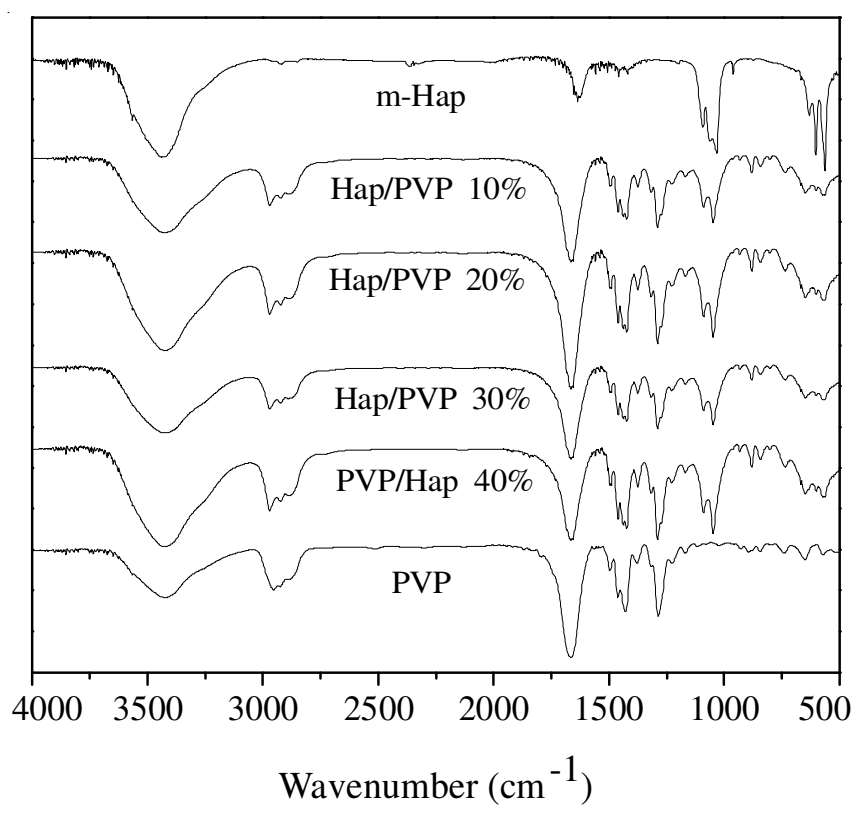

Fig. 1. FT-IR spectra of pure PVP, $m$-Hap and Hap/PVP nanocomposites

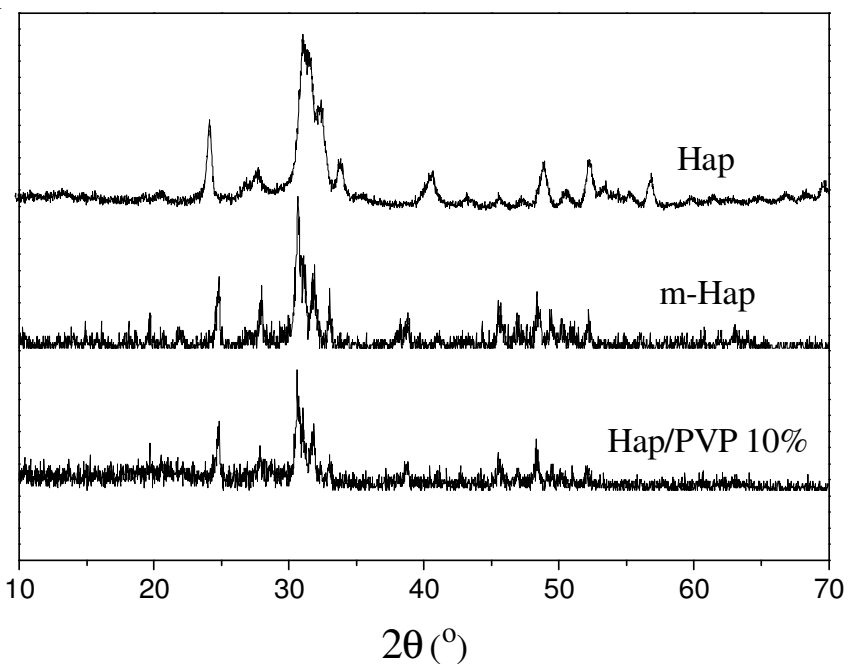

Fig. 2. X-ray diffraction of m-Hap, pure PVP and Hap/PVP nanocomposites

fully meeting the standard card of Hap (JCPDS 09-432). Hap/ PVP indicates a similar XRD pattern of Hap, revealing that Hap/PVP contained Hap phase.

SEM: The SEM images of Hap/PVP with Hap contents at $20 \%, 30 \%$ and $40 \%$ are displayed in Fig. 3. All three Hap/ PVP nanocomposites show a porous structure, which is similar to natural bones. It's hard to distinguish the Hap phase from the PVP matrix, indicating that the copolymerization process leads to fully dispersion of Hap in the PVP matrix. Therefore, Hap/PVP shows a potential application in tissue engineering.

TG and DSC analyses: DSC measurements have been carried out to get the glass transition temperatures of the prepared samples. The DSC thermographs of the Hap/PVP nanocomposite and PVP are recorded in Fig. 4. $\mathrm{T}_{\mathrm{g}}$ of PVP is $150.5^{\circ} \mathrm{C}$ and $\mathrm{T}_{\mathrm{g}}$ of Hap/PVP nanocomposite with Hap content of $10 \%$ is $163.4{ }^{\circ} \mathrm{C}$, which is $12.9{ }^{\circ} \mathrm{C}$ higher than PVP. The explanation is that the introduction of nanoscale Hap particles into PVP matrix has blocked the free movement of PVP chains, leading to the promotion of $\mathrm{T}_{\mathrm{g}}$.

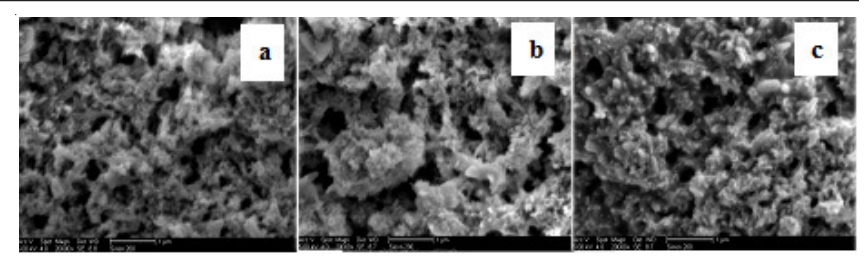

Fig. 3. SEM images of Hap/PVP with different Hap content. a: Hap content is $20 \%$; b: Hap content is $30 \%$; c: Hap content is $40 \%$

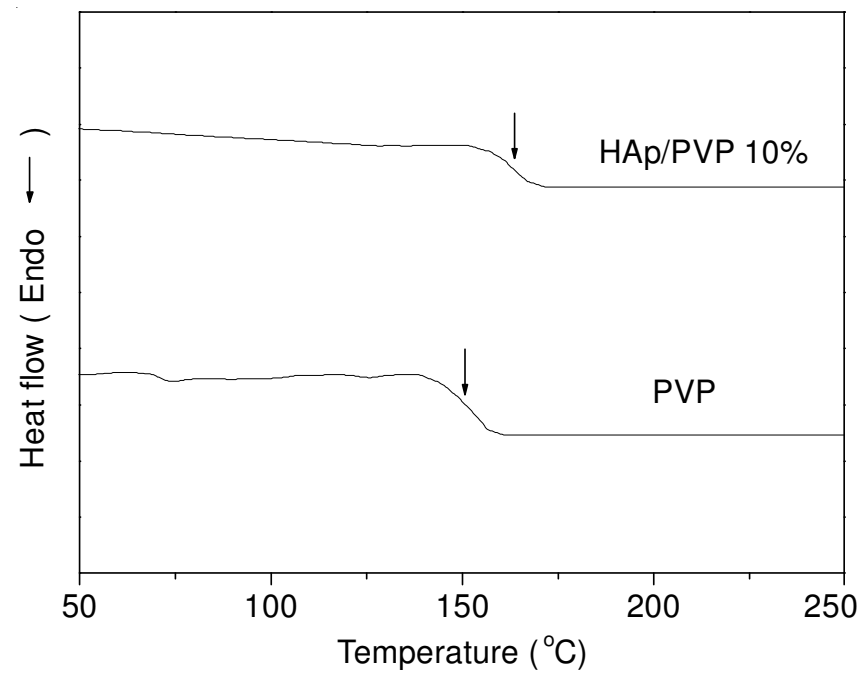

Fig. 4. DSC thermographs of PVP and Hap/PVP

The TGA thermographs of pure PVP and Hap/PVP with $10 \%$ content of Hap are indicated in Fig. 5. The decomposition temperature $\left(\mathrm{T}_{\mathrm{d}}\right)$ of pure PVP is about at $390.3^{\circ} \mathrm{C}$ and $\mathrm{T}_{\mathrm{d}}$ of Hap/PVP is $409.3{ }^{\circ} \mathrm{C}$, which is $19.0^{\circ} \mathrm{C}$ higher than PVP. This $T_{d}$ increase could be explained by the nanometer effect and shielding effect of nanoscale Hap which slow down the degradation of PVP molecular chain.

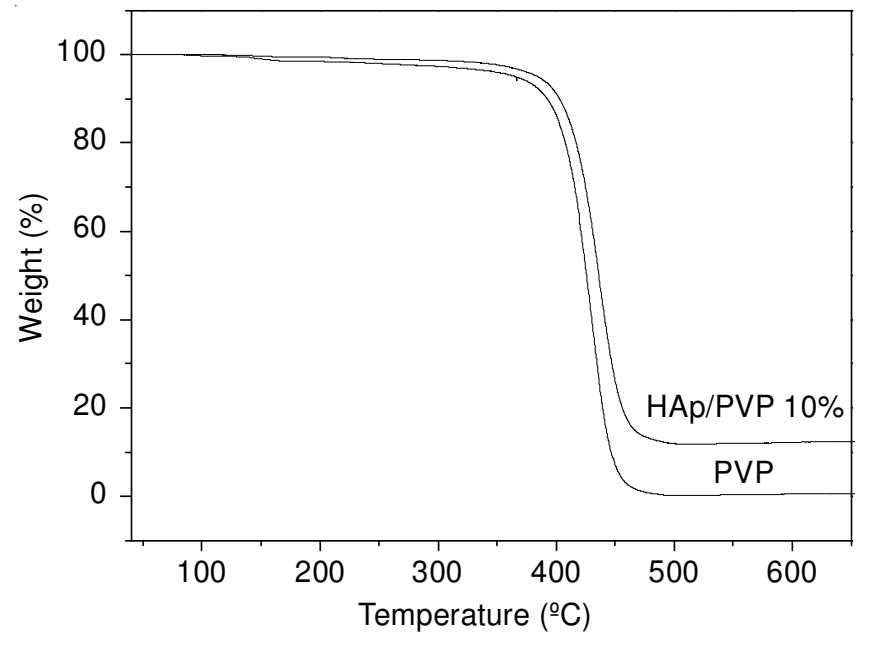

Fig. 5. TGA thermographs of PVP and Hap/PVP

\section{Conclusion}

Hap/PVP nanocomposite material was synthesized by in situ polymerization and characterized by SEM, XRD and FTIR. The result shows that we have obtained the designed composite material. Hap/PVP nanocomposite material was tested and analyzed with TGA and DSC, which indicate that 
thermal property of Hap/PVP has been obviously improved as the addition of Hap nanoparticles.

\section{ACKNOWLEDGEMENTS}

This work was financially supported by the Natural Science Foundation of Anhui Educational Department (No. KJ2011A247) and the Natural Science Foundation of Anhui Province (No. 1208085MB24).

\section{REFERENCES}

1. A. Stanculescu, L. Tugulea, H.V. Alexandru, F. Stanculescu and M. Socol, J. Cryst. Growth, 275, 1779 (2005).

2. H.W. He, K. Li, J. Wang, G.H. Sun, Y.Q. Li and J. Wang, Mater. Design, 32, 4521 (2011).

3. C.C. Chen, D.J. Lin, T.M. Don, F.H. Huang and L.P. Cheng, J. Non-Cryst. Solids, 354, 3828 (2008).

4. X.B. Zhang and N. Liu, Int. J. Refract. Met. Hard Mater, 26, 575 (2008).

5. Q.W. Song, Y. Li, J.W. Xing, J.Y. Hu and M. Yuen, Polymer, 48, 3317 (2007).

6. L. Mohan, D. Durgalakshmi, M. Geetha, T.S.N.S. Narayanan and R. Asokamani, Ceram. Inter., 38, 3435 (2012).

7. A.A. Khan and T. Akhtar, Solid State Sci., 13, 559 (2011). 